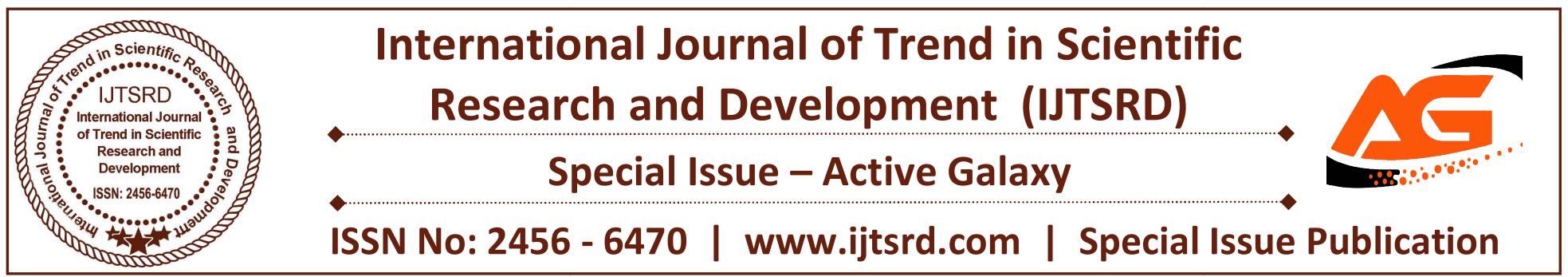

\title{
Controlling Traffic Signals Through GPS for Ambulance
}

\author{
Mrs. S. DurgaDevi ${ }^{1}$, Mr. P. Senthil ${ }^{1}$, T. Keerthana ${ }^{2}$ \\ ${ }^{1}$ Assistant Professor, ${ }^{2} \mathrm{PG}$ Scholar \\ ${ }^{1}$ Department of Computer Science and Engineering, ${ }^{2}$ Dept. of Master of Computer Applications \\ Veltech Hightech Dr Rangarajan Dr Sakunthala Engineering College \\ Avadi, Chennai, India
}

\begin{abstract}
In today's world, traffic jams during rush hours is one of the major interest. During surge hours, Emergency vehicles like Ambulances get caught in jams. Due to this, these emergency vehicles are not able to reach their target in time, resulting into a loss of human lives. We have Developed a system which is used to provide clearance to any emergency Ambulance vehicle by Turning all the red lights to green on the path of the emergency vehicle, hence providing a Complete green bay to the desired vehicle. A green bay is the synchronization of the green phase Of traffic signals. With a "green bay" setup, a vehicle transient through a green signal will continue to receive green signals as it travels down the road. Around the world, green bay is used to great effect. In the existing system we don't have automatic control traffic signal, due to this Emergency ambulance not able to reach the hospital within time. For this system we have implemented effective smart ambulance system by using GPS Technology. This project is Targeted to design and develop a real time smart ambulance system.
\end{abstract}

Keywords: Traffic Signals, Ambulance, GPS

\section{Introduction}

These days with the increase in the population and due to luxurious living there is an increase in the traffic on roads. Amidst all these frenzied life, one forgets the importance of human life .This is a very serious problem even in case of road accident one even doesn't care to call the emergency unit. On road due to high traffic people are unable to provide the free way to the emergency unit which also becomes one of the factors of late first aid to the patient due to which one can die on the way to hospital. So to conquer their negative factors and to provide the first aid to the prey this system -"Intelligent Ambulance with automatic traffic control" is proposed in this paper. This paper describes the working of accident detection and immediately alerting the emergency ambulance unit about the accident with the location co-ordinates, receiving such co-ordinatesthe ambulance unit or so called emergency unit respond immediately and leaves for the accident location. Now while moving toward the location or while taking the patient to the hospital there may or may not occur some traffic so in order to free or release the traffic the intelligent ambulance controls the traffic light itself such that the traffic light converts in a manner so that it could receive the free way to the hospital. Intelligent ambulance also have some extra features such as while in the way to hospital before providing the first aid to the patient one can detect the patient health status like monitoring the fever or pulse rate so that the patient can get the correct first aid treatment and can save his life. Koushik Mandal, Arindam Sen, Abhijnan Chakraborty and Siuli Roy, "Road Traffic Congestion Monitoring and Measurement using Active RFID and GSM Technology" IEEE

2 Literature Survey:

2.2 TITLE : SURVEY ON VARIOUS INTELLIGENT TRAFFIC MANAGEMENT SCHEMES TO MINIMIZE CONGESTION FOR EMERGENCY VEHICLES 
DECRIPTION: Intelligent Traffic Signal Control System by Dinesh Rotake \& Prof. Swapnili Karmoe[1] (2012). Here system uses IR sensors, AVR-32 microcontroller with programmable flash memory and built in 8-channels ADC. IR (i.e. Infrared) sensor is programmed to detect emergency vehicle and microcontroller is designed in such a way to give red signal to all other lane but one with emergency vehicle. Limitations: Here IR sensors are used, due to various climate conditions present in India, IR sensors may need to keep in safe place or a strong box. Price factor of implementation of this system is high. So it is not desirable to execute this system. Design of Intelligent Ambulance and Traffic Control. Ambulance will consist of Heart Beat and Temperature sensor. When key is pressed, heart beats and temp values will be sent to pre-defined mobile phone (Hospital) using GSM. On signal there will be two RFID readers which will detect traffic density on two roads. When ambulance is detected on any road signal for that side will be green. Limitations: All ambulances must equip with special instruments other than medical. Some other integration also needs to implement this system. RFID tags are not reliable because they fail in short period of time.

2.2 TITLE: Intelligent Traffic Management for Ambulance and VIP Vehicles

DESCRIPTION: The paper titled "Implementing Intelligent Traffic Control System for Congestion Control Ambulance Clearance and Stolen Vehicle Detection" [1], tells about intelligent traffic control systems to pass emergency vehicles smoothly. Each seperate vehicle is equipped with special Radio Frequency Identification tags, RFID reader is used to read the tags attached to the vehicle. It also determines network congestion and hence the green light duration for the path. Also in this project a message will be sent using GSM SIM 300 to the police control room unlike in our project. The project is implemented only for single road where as our project depicts Multi-road junctions. This paper introduces the structural, technical targets and applications of AVI system based on the RFID giving a unique advantage in data collection and data transmission. This project is only based on AVI system where as our project is based on traffic congestion management.

2.3 TITLE : Implementation of Ambulance Rescue System Using Lab VIEW (IARS)
DESCRIPTION: In this paper "Traffic accident automatic detection and remote alarm device"(2011),it has an important cons regarding detection of minor and major accidents. But we have given an special user interface to halt the further process in case of minor accident.2) In an "intelligent accident detection and ambulance- rescue system"(2014), the accident information is sent only to ambulances. In our IARS message is sent to relatives as well as main server.3) In "An advanced algorithm for finding shortest path in car navigation system" (2008), they preferred unidirectional communication with ambulance. But we implemented bi-directional communication to check availability of ambulances.

\subsection{TITLE : Automatic Vehicle Accident Detection} and Rescue System

DESCRIPTION: At present standards, we cannot detect where the accident has happened and hence no information related to it, foremost to the death of an individual. The examiner work is going on for trailing of the vehicle level in dark clumsy areas where there is no network for taking the signals. In writing a number of methods to provide security and safety through displaying the vehicle's real time accurate location and information using different technologies have been planned. A good survey of using GPS, GSM and GIS has been granted in and The general device is to provide the real time spatial position of a vehicle using GPS receiver and send this data to GSM centre through versatile software, this is all done by the watching centre which is working as a control unit that is connected not only by an optical cable but also connected wirelessly through TCP/IP protocols. The monitoring centre allocates the data to the client in an clear format and it also stores the movement records and displays the real time data about vehicle on electronic map through GIS

\subsection{TITLE: Accident Location Detection Using} Vehicle Tracking System

DESCRIPTION: This paper presents a new design called AARS (Automatic Ambulance Rescue System) to reduce the time for the ambulance to reach the hospitals in time and thus decreasing the end of the patients by controlling the ambulance to know the accident spot through sensors, choose suitable route to reach hospital and controls the traffic lights.[1] A new scheme called ITLS (Intelligent Traffic Light system to provide a smooth flow for the emergency 
vehicles like ambulance to reach the hospitals in time and thus minimizing the delay caused by traffic congestion by automatically controlling the traffic lights in the path of the ambulance making use of GPS is explained in this paper. [2] This document gives a complete idea on interfacing the GPS and GSM modules to ARM microcontroller (LPC2148) with examples in $\mathrm{C}$ language. [3].

\section{Work Analysis:}

\subsection{Accident Disclosure and alerting System:}

This project is Accident Disclosure And Alerting System Using 8051 Microcontroller. When an individual riding his/her bike, meets with an accident, there is a chance that the individual may suffer from a serious injury or expire instantaneously and there is no one around to help him. Well this system is a solution to the problem.

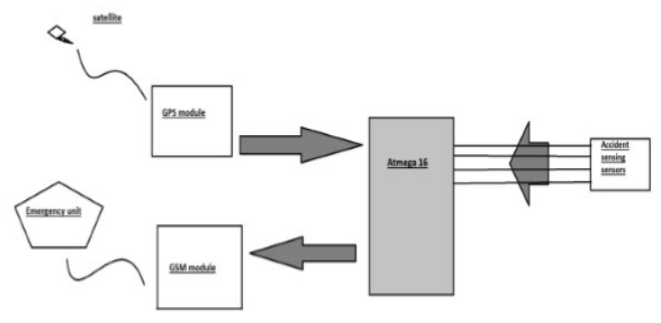

\section{ATMEGA 16 Microcontrollers GPS \\ GSM \\ Sensors (pressure, vibration etc) \\ Emergency unit \\ Satellite}

Fig 1. Accident Alerting Mechanism

\subsection{Traffic Control System:}

Provide a compendium of existing traffic control system technology, Aid understanding of the basic elements of traffic control systems, Broaden the viewpoint of the traffic management field, Serve as a basic relation for the using traffic engineer in planning, designing, and implementing new and useful traffic control systems, and Serve as a training aid in the field of traffic control systems.

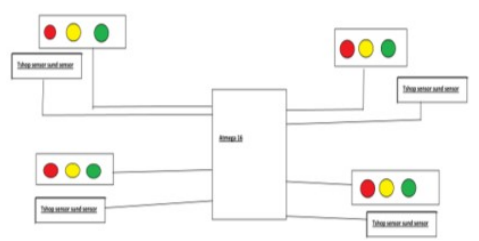

Fig 2.Traffic Control System

Micro-controller ATMEGA 16

Led(red, yellow, green)
Seven segment

Tshop sensor

Sound sensor

\subsection{Health Monitoring System:}

A health monitoring system which tracks the state of health of a patient and compiles a chronological health history of the patient uses a multi parametric monitor which periodically and automatically measures and records a plurality of physiological data from sensors in contact with the patient's body. The data collected is not specifically related to a particular medical condition but, instead, provides the information necessary to derive patterns which are characteristic of healthy patients as well as those who are ill. The data collected is periodically uploaded to a database in which it is stored along with similar health histories for other patients.

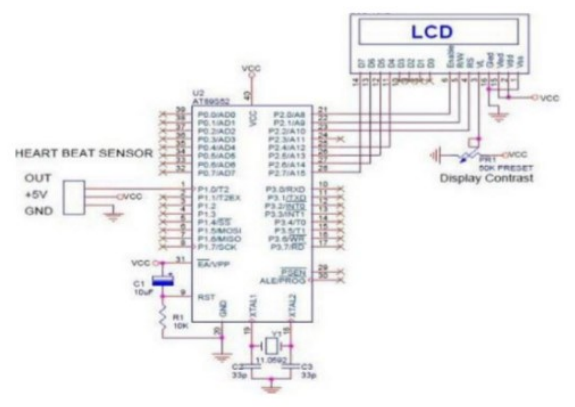

\section{Heart Rate}

ATMEGA 16

Microcontroller

Hospital

LCD

Body

Temperature

\section{Evaluation Techniques:}

Vehicle section

Ambulance section

Traffic section

\subsection{VEHICLE SECTION}

The vehicle unit installed in the vehicle senses the accident and sends the position of the accident to the controller. According to our system, every vehicle should have a vehicle unit. The vehicle unit consists of a vibration sensor, controller, siren, a user interface, GPS system and a GSM module. The oscillation sensor used in the vehicle will all the time sense for any large scale oscillation in the vehicle. The sensed data is given to the controller GPS SYSTEM inside the vehicle. 


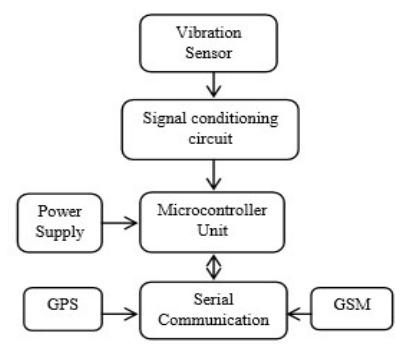

Fig 4. VEHICLE SECTION

\subsection{AMBULANCE SECTION}

The controller finds the nearest ambulance to the accident spot and also the shortest path between the ambulance, accident spot and the nearest hospital. The controller then sends this path to the ambulance. Also using this information the manager controls all the traffic signals in the path of ambulance and makes it ready to offer free path to ambulance, which ensures that the ambulance reaches the hospital without delay. At the same time, the ambulance unit turns ON the RF transmitter. This will lead to communicate with the traffic section. In manage section GSM modem receives information concerning accident and send it to PC. PC locates the immediate ambulance and ambulance is learned to pick up the patient. Control section transmits the control signal to all the signals in between ambulance and vehicle by RF transmission.

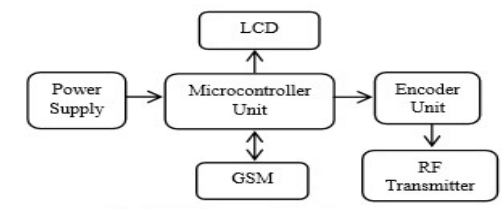

Fig 5. AMBULANCE SECTION

\subsection{TRAFFIC SECTION}

Whenever traffic signal part receives the data regarding accident, the $\mathrm{RF}$ receiver in this part is revolved $\mathrm{ON}$ to search for ambulance approaching the traffic signal. Whenever the ambulance arrives near to the traffic signal(approximately $100 \mathrm{~m}$ ), the traffic signal will be made to green through RF connection. Thereby the ambulance is allowed to reach the hospital in time.

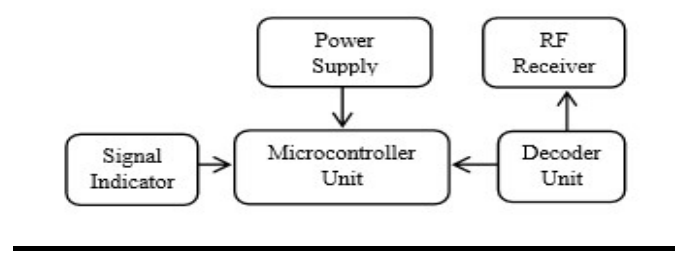

Fig 6.TRAFFIC SECTION

\subsection{Components List: \\ PIC16F877. \\ GPS Receiver with Antenna. \\ GSM Modem. \\ Microcontroller 8051. \\ RF module \\ LCD.}

\section{METHODOLOGIES:}

The main server on receiving the accident spot location starts to find all the nearest available ambulances around the accident location. In order to achieve this, we have to feed the databases about the ambulances location in prior to the Lab VIEW. Then it compares the location and find out the nearest ambulances. After that main server will send the accident spot location to the nearest availability ambulances [4].

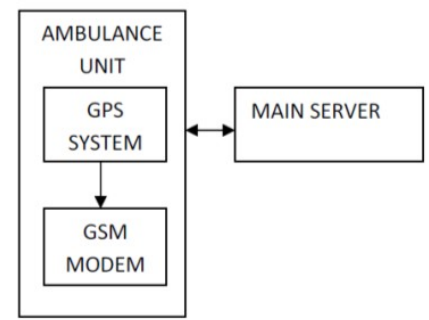

Fig 7. Ambulance Unit

\subsection{SHORTEST PATH ALGORITHM:}

Step1 : Receiving the location of ambulance 1 by main server

Step2 : After 10 seconds it receives the location of ambulance2.

Step3 : In an interval of 10 seconds it receives the location of ambulance 3

Step4 : Calculating the nearest ambulance using Lab VIEW.

Step5 : Transmission accident location to the internal measured ambulance.

Step6 : Contemporary ambulance extends the hospital without any time lag.

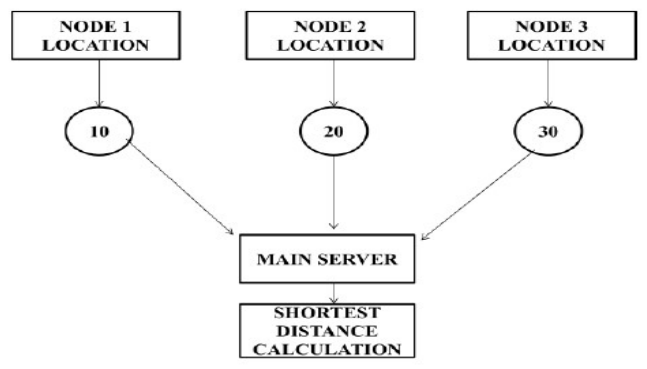

Fig 8.Flow Chart of shortest path algorithm 


\section{FUTURE ENHANCEMENT:}

The proposed work considers not only the priority of the vehicles but also the density of the vehicles on the road and Controls the traffic light order well and more properly and the precision of the RFID is more than Camera's so it also enhances the performance of traffic light Violation Detection System. Also as a future scope the condition of patient can be monitored and this information is sent to the respective doctor so that doctor can prepare for the next process before the patient reach to the hospital. Traffic lights can be extended to $\mathrm{N}$ number and traffic light control can be done for whole city by session on a single place. In ambulance system, the data of the patient in the ambulance can be sent to the Hospitals via GSM technology. Thus, it can provide early and fast treatment of the patient. In the future, this system can be extended to more applications. We can facilitate connectivity to the nearest hospital and provide medical assistance through live streaming from the ambulance and also through video conferencing.

\section{CONCLUSION:}

This project offers vehicle accident detection and alert system with SMS to the user defined mobile numbers. The GPS tracking and GSM alert based algorithm is designed and implemented with LPC2148 MCU in embedded system domain. The proposed Vehicle accident detection system can trace part data cut and sends an alert SMS regarding accident. Experimental work has been carried out carefully. The result shows that higher sensitivity and accuracy is indeed achieved using this project. EEPROM is interfaced to store the mobile numbers permanently. This made the project more user friendly and reliable. The proposed method is verified to be highly beneficial for the automotive industry.

\section{REFERENCE:}

1. Addala Suryanarayana Murthy, IIT.Ravindra "Accident Location Detection Using Vehicle Tracking System" (IJARET) Vol. 2, Issue 3 (July - Sept. 2015).

2. Mr. Binod Kumar1, Mr. Pintu Kumar2, Mr. Suman Kumar3, Mr. Suraj. R. Dhande4, Prof. Suhas. D. Kakde "Automatic Vehicle Accident Detection and Rescue System" (IJRASET) Volume 4 Issue IV, April 2016.

3. Mr.G.MYILSAMY1, AKILAN A2, ASMITHA G.R3, GOPINATH P4, KOWSALYA S5 “
Implementation of Ambulance Rescue System Using LabVIEW (IARS)" (IRJET) Volume: 04 Issue: 03 | Mar -2017.

4. Nangare Yogini Ahmednagar, "Intelligent Ambulance Rescue System" (IJRCCT) Vol 3, Issue 7, July - 2014.

5. Devika M D1 "Intelligent Traffic Management for Ambulance and VIP Vehicles" (IJIRSET) Vol. 5, Issue 8, August 2016.

6. Swet Nisha1, Sanatan Ratna "SURVEY ON VARIOUS INTELLIGENT TRAFFIC MANAGEMENT SCHEMES TO MINIMIZE CONGESTION FOR EMERGENCY VEHICLES" (IJSTM) Volume No.04, Issue No. 01, January 2015.

7. Supriya Sawwashere, Ashutosh Lanjewar "Automated Accident Intimation and Rescue System for Vehicles" (IJAIEM) Volume 4, Issue 5, May 2015.

8. Saurabh Kapoor1, Parul Gupta2, Pooja Sharma3, Prabhu Nath Singh4 " Intelligent Ambulance with Automatic Traffic Control" (IRJET) Volume: 04 Issue: 04 | Apr -2017.

9. Hrishikesh Murkut1, Fazal Patil2, Vishal Yadav3, Meghana Deshpande4 "Automatic Accident Detection and Rescue with Ambulance" (IJECE) Volume 2 Issue 6-June 2015.

10. Katsunori Tawara, Naoto Mukai, "Traffic signal control by using Traffic congestion prediction based on Pheromone Model", Proceedings of 22nd IEEE International Conference on Tools with Artificial Intelligence, pages:27-30, 2010

11. Zhaosheng Yang. "Study on the schemes of traffic signal timing for Priority Vehicles Based on Navigation System", Proceedings of International Vehicle Electronics Conference, pages: 249-254, 2001

12. Road Traffic Congestion Monitoring and Measurement using Active RFID and GSM Technology by Koushik Mandal, Arindam Sen, Abhijnan Chakraborty and Siuli Roy, IEEE Annual Conference on Intelligent Transportation Systems, 2011.

13. Malik Tubaishat, Qi Qi, Yi Shang, Hongchi Shi "Wireless Sensor-Based Traffic Light Control" IEEE CCNC 2008 proceedings 1-4244-1457-1/08 
Special Issue - Active Galaxy

14. Abu-Lebdeh, G. and Ahmed, K., "Assessment of operational advantages of intelligent traffic control in congested conditions", presented at the 9th ITS World Congress, Chicago, October 2002

15. Malik Tubaishat, Qi Qi, Yi Shang, Hongchi Shi "Wireless Sensor-Based Traffic Light Control" IEEE CCNC 2008 proceedings 1-4244-1457-1/08.

16. Image Processing Based Intelligent Traffic Controller by Vikramaditya Dangi, Amol Parab, Kshitij Pawar and S.S Rathod. Undergraduate
Academic Research Journal (UARJ), ISSN : 2278 - 1129, Vol-1, Iss-1, 2012.

17. Koushik Mandal, Arindam Sen, Abhijnan Chakraborty and Siuli Roy, "Road Traffic Congestion Monitoring and Measurement using Active RFID and GSM Technology" IEEE

18. Priority Based Traffic Lights Controller Using Wireless Sensor Networks by Shruthi K R and Vinodha K, International Journal Of Electronics Signals And Systems (IJESS) ISSN: 2231- 5969, Vol-1 Iss-4, 2012 